\title{
Electronic marketplaces: A literature review and a call for supply chain management research
}

\author{
Martin Grieger \\ Department of Operations Management, Copenhagen Business School, DK-2000 Frederiksberg, Denmark
}

\begin{abstract}
These days, Internet-based electronic marketplaces (EMs) are getting more and more popular. They emerge in different industries, supporting the exchange of goods and services of different kinds, with and for different types of actors, and are following different architectural principles. Most observers have assumed that EM would come to dominate the e-business landscape. Once you look beyond the publicity, however, you quickly see that most EMs are struggling. The supply chain dimension of an EM is largely neglected and poorly managed, while basic logistics operation is currently hampering turnover and revenues. The Paper at hand examines, based on a critical literature review, the actual EM discussion and calls for more supply chain management research within this field.
\end{abstract}

(c) 2002 Elsevier Science B.V. All rights reserved.

Keywords: Supply chain management; Electronic marketplaces; Electronic business; Relationships; Electronic commerce; Information technology

\section{Introduction}

The world of business is being changed to an e-economy by new forces global competition, increased information availability, educated consumers, changing relationships, rapid innovations, and increasingly complex products. No industry is left untouched. In today's customer-focused marketplace, supply chain management has become a key to competitive advantage. But having accepted the challenge to create a synchronised supply chain that can compete in the future e-economy, what concrete capabilities must then be mastered? We see an increase in the number and functionality of business models that use information systems that cross organisational boundaries, such as systems

E-mail address: mg.om@cbs.dk (M. Grieger). linking one or more firms with customers and/or suppliers. New business models emerge or old business models improve and experience a renaissance. But they all have a very short history and still have to prove their profitability and function. So why not instead ask the question: Which competencies must a business model, using the Internet medium, manage amidst a competition regarding "supply chain versus supply chain"? One of these business models is an "Internet-based B2B electronic marketplace" (EM), which this paper is dealing with.

\section{Methodology}

This paper provides a survey of the EM discussion and presents an EM definition (Section 3). 
Next, the paper exposes the importance of supply chain management within EMs (Section 4). In Section 5 the relevancy of supply chain management for an EM is analysed by examining the type of relationship within different EM categories.

A standard literature review was conducted along with a key word search of the World Wide Web. The investigation included international journals as well as reports from smaller journals, conference papers and the "grey" literature (i.e., popular articles, unpublished reports and other documents, and some Internet (non-journal) materials). First, relevant keywords, such as "electronic marketplace", "electronic SCM", "electronic exchange", and "electronic auction" were defined. Then, a search in electronic scientific databases, internet portals and websites of relevant consultant and research firms was conducted; various search engines were used (see Appendix A for a description of the methodological approach to the search process).

\section{Introducing electronic marketplaces}

\subsection{The jargon jungle and the problem of under- standing electronic marketplaces}

E-commerce can be take place among businesses (B2B) or between businesses and consumers (B2C) but the Internet also encompasses a wider spectrum of potential commercial activities and information exchanges and chances for an EM intermediary (see Fig. 1). Many of these EMs have been established on the Internet since the middle of 1999. The Economist estimates that there were already over 750 EMs in existence in the first quarter of 2000 (The Economist, 2000).

The EM concept, however, dates back to mid 1940s when the first documented EM system, known as Selevision, was used to remote-market Florida citrus fruit (Henderson, 1984). Real developments in EMs, however, only started in the late 1970s when the first computer-based EM pilot project was initiated (McCoy and Sarhan, 1988). During its history, the core function of the EM facilitating trading transactions for buyers and/or sellers-has remained. It seems that only innova-

\begin{tabular}{c|c|c|c|}
\multicolumn{1}{c}{ Government } & \multicolumn{1}{c}{ Government } & \multicolumn{1}{c}{ Business } & Consumer \\
\cline { 2 - 4 } Business & $\begin{array}{c}\text { G2G } \\
\text { e.g. coordination }\end{array}$ & $\begin{array}{c}\text { G2B } \\
\text { e.g. information }\end{array}$ & $\begin{array}{c}\text { G2C } \\
\text { e.g. information }\end{array}$ \\
\cline { 2 - 4 } Consumer & $\mathbf{B 2 G}$ & $\mathbf{B 2 B}$ & $\mathbf{B 2 C}$ \\
e.g. & $\begin{array}{c}\text { e.g. e-commerce, } \\
\text { e-markets } \\
\text { (Covisint.com) }\end{array}$ & $\begin{array}{c}\text { e.g. e-commerce, } \\
\text { (Amazon.com) }\end{array}$ \\
\cline { 2 - 4 } & $\begin{array}{c}\text { C2B } \\
\text { e.g. tax } \\
\text { compliance }\end{array}$ & $\begin{array}{c}\text { e.g. price } \\
\text { comparison, } \\
\text { e-markets } \\
\text { (priceline.com) }\end{array}$ & $\begin{array}{c}\text { e.g. e-markets } \\
\text { (eBay.com) }\end{array}$ \\
\hline
\end{tabular}

Fig. 1. Internet applications (Coppel, 2000).

tion has been the medium underlying the market mechanism, which has been developed from analogue telephone systems to digital computer networks.

As new entrants with new business models pour into the B2B space, it is increasingly difficult to make sense of the new EM landscape. Due to the new technology of Internet technology, EMs became more and more interesting for both researchers and practitioners because the limiting factors of time and space seem to have been overcome by the new medium. Via the Internet, EMs are ubiquitous and available 24 hours a day (Schmid, 1993; Weber, 1993). They seem to be more "just" and "self-ruled" as well as more competitive and decentralised (Himberger et al., 1991; Malone et al., 1987). Following these arguments, EMs could be considered manifestations of the neoclassical market ideal, reducing transaction costs to a negligible minimum (Schmid, 1993; Bakos, 1991). New EM viewpoints have grown and its research is popular in a range of disciplines, though definitions are varying, attributes and characteristics seem to be innumerable and used arbitrarily (see Table 1).

Is an EM an interorganisational information system (Bakos, 1991), an electronic procurement solution (Segev et al., 1999), a medium (Schmid et al., 1998), a meeting point (Kaplan and Sawhney, 2000), an intermediary (Dai and Kauffman, 2000) or just a listing (Bradley and Peters, 1997)? Beyond that, some authors argue for special attributes such as virtual (Segev et al., 1999), digital (Dai and Kauffman, 2000), public (Ariba, 2000; 
Table 1

Selected EM definitions

\begin{tabular}{|c|c|}
\hline Author (s) & Selected EM definitions \\
\hline $\begin{array}{l}\text { McCoy and } \\
\text { Sarhan (1988) }\end{array}$ & $\begin{array}{l}\text { "An EM separates the negotiating function from the physical transfer of the product or commodity in which the } \\
\text { market trades. It can manage buyers' and sellers' offers and bids, as well as moving products directly from sellers } \\
\text { to buyers. The system is open to all buyers and sellers, regardless of their location and can provide instant market } \\
\text { information to all traders" }\end{array}$ \\
\hline Bakos (1991) & $\begin{array}{l}\text { "...is an interorganisational information system that allows the participating buyer and sellers to exchange } \\
\text { information about prices and product offerings" }\end{array}$ \\
\hline $\begin{array}{l}\text { Bradley and } \\
\text { Peters (1997) }\end{array}$ & $\begin{array}{l}\text { "... can be viewed as a public listing of products and their attributes from all suppliers in an industry segment, } \\
\text { and available to all potential buyers" }\end{array}$ \\
\hline Bakos (1998) & $\begin{array}{l}\text { "... facilitating the exchange of information, goods, services, and payments. In the process, they create economic } \\
\text { value for buyers, sellers, market intermediaries, and for society at large" }\end{array}$ \\
\hline $\begin{array}{l}\text { Schmid et al. } \\
\text { (1998) }\end{array}$ & "... is a media which foster market based exchanges between agents in all transaction phases" \\
\hline $\begin{array}{l}\text { Segev et al. } \\
(1999)\end{array}$ & $\begin{array}{l}\text { "Compared to many other electronic procurement solutions, EMs represent a relatively neutral position between } \\
\text { buyer and seller, providing services to both sides of a transaction. An EM represents a virtual place where buyers } \\
\text { and sellers meet to exchange goods and services" }\end{array}$ \\
\hline $\begin{array}{l}\text { Dai and Kauff- } \\
\text { man }(2000)\end{array}$ & $\begin{array}{l}\text { "... function as digital intermediaries that focus on industry verticals or specific business functions. They set up } \\
\text { marketplaces where firms participate in buying and selling activities after they obtain membership" }\end{array}$ \\
\hline Mueller (2000) & $\begin{array}{l}\text { "Electronic markets allow buyers and sellers to exchange information about product offerings and prices bid and } \\
\text { asked" }\end{array}$ \\
\hline Ariba (2000) & $\begin{array}{l}\text { "... are commerce sites on the public Internet that allow large communities of buyers and suppliers to "meet" and } \\
\text { trade with each other. They present ideal structures for commercial exchange, achieving new levels of market } \\
\text { efficiency by tightening and automating the relationship between supplier and buyer" }\end{array}$ \\
\hline $\begin{array}{l}\text { Kaplan and } \\
\text { Sawhney (2000) }\end{array}$ & "... is a meeting-point where suppliers and buyers can interact online" \\
\hline $\begin{array}{l}\text { Lipis et al. } \\
(2000)\end{array}$ & $\begin{array}{l}\text { "... is an Internet-based solution that links businesses interested in buying and selling related goods or services } \\
\text { from one another. It can be distinguished from a procurement or distribution system insofar as it must be neutral, } \\
\text { taking into account the interests of both buyers and sellers in its governance" }\end{array}$ \\
\hline
\end{tabular}

Bradley and Peters, 1997), neutral (Segev et al., 1999), or open (McCoy and Sarhan, 1988). These examples show that the vocabulary, which is used to describe this new area of business, is under establishment. Within the "e-hub name game" (Obrecht, 2000) the name EM barely prevails against other terms and concepts like B2B marketplaces, e-hubs, e-markets, exchanges, auctions, portals seem to overlap and mean different things to different people. In the following section an attempt is made to set out a clear definition of an EM.

\subsection{An electronic marketplace definition}

A marketplace as a historically evolved institution allows customers and suppliers to meet at a certain place and at a certain time in order to communicate and to announce buying or selling intentions, which eventually match and may be settled. Today the institution market still does the same, but has occasionally been remodelled due to the evolution of media. However, owing to the evolution of modern information and (tele-) communication technology, time and space restrictions have been weakened and the cyberspace has become the new meeting point.

The unique feature of an EM is that it brings multiple buyers and sellers together (in a "virtual" sense) in one central market space. If it also enables them to buy and sell from each other at a dynamic price which is determined in accordance with the rules of the exchange, called an electronic exchange; otherwise it is called a portal. The important point, which differentiates an exchange from other B2B e-commerce companies, is that an exchange involves multiple buyers and sellers and it centralises and matches buy and sell orders and provides post-trade information. One should compare this with the e-procurement process of 
one company, say General Motors, which sets up a web site with an auction process for suppliers to bid on contracts with General Motors. This is not an EM-because there is only one buyer. Similarly, a business that offers goods or services for sale to other businesses, over the Internet, is not an EM even if it provides a price-setting mechanism that is normally associated with an EM, such as an auction-because there is only one seller.

To summarise these thoughts and show different views (Schmid, 1999), an EM could be defined as

(a) institutional - as a medium

- that assigns different roles within a community, primarily buyers and suppliers, but also other roles like logistics service providers, banks, and other intermediaries;

- that facilitate the exchange of information, goods, services, and payments;

- that provide an infrastructure-define protocols and processes that rule the inter action within the community, and also provide a common language.

(b) social - as a community consisting of buyers, sellers, etc.

- which could be described by a certain condition, which includes the participants' knowledge, intention, contracts (assets and liabilities) and goods, at a certain time;

- with roles involving rights and duties;

- which intends to use market transactions exchange - or communication procedures - in order to change their condition according to their intention.

Other examinations are also thinkable as well, for example an economic view or a legal view.

\section{Supply chain management and electronic markets}

\subsection{Why electronic marketplaces need to (re) act}

Most observers have assumed that EMs would come to dominate the B2B landscape. Once you look beyond the publicity, however, you soon realise that most EM are floundering and are adorned with their enormous number of users or members, their huge product list, the number of offers to sell or requests to buy that are placed on their website each day; or the quantities that have been traded. The number of completed transactions, on the other hand, is much smaller than the number of members.

Wise and Morrison (2000) name three fatal flaws of EMs: "First, the value proposition offered-competitive bidding among suppliers allows buyers to get the lowest possible prices-runs counter to the best recent thinking on buyer-supplier relations." In their "purest" sense, markets are characterised by an infinite number of anonymous participants, perfect information transparency and instant competition based on (dynamic) price alone (Tapscott et al., 2000). Although such a scenario promises maximum economic welfare via optimal allocation of resources, it is at as the same time highly unrealistic as it results in a situation where corporate profit margins are approaching zero. Other factors, such as quality, timing of deliveries, and customisation, are often more important than price in determining the overall value provided by a supplier. Many companies have spent the last years in managing their supply chain links and/or have spent the last decades methodically forging tighter, more strategic relationships with suppliers; many such affiliations have involved joint product-design efforts, integration of complex processes, and long-term service contracts (Wise and Morrison, 2000). Second, Wise and Morrison state that EMs deliver little benefit to sellers: "Yes, suppliers have access to more buyers with only a modest increase in marketing cost, but that benefit is overwhelmed by pricing pressure. Few suppliers want to be anonymous contestants in ruthless bidding wars, and for the highestquality, most innovative suppliers, price battles are anathema." Finally, the business models of most EMs are, at best, "half-baked". In their rush to get on-line, the companies that run the EM have not taken the time to study their customers' priorities in depth, to create distinctive offerings, or even map out paths to profitability.

Perhaps the most critical question is whether the technology or the EM itself exacerbates antitrust problems. Susan DeSanti, director of policy 
planning at the Federal Trade Commission (FTC) in Washington states that "anytime there is some kind of a purchasing joint venture among competitors, it has the potential to raise antitrust issues" (Nash, 2000). The competitor watches what everybody else does, taking advantage of this new electronic window into a process that used to be carried out more discreetly with papers, phones and personal meetings (Nash, 2000).

The question has been raised whether the age of the new economy will reserve a place for these intermediaries, given that new technologies facilitate direct links between supply chain members, such as manufacturers and end consumers of products, or businesses and their suppliers. But, nevertheless, many researchers state that supply chain management is a necessity for EMs. The next section reviews their argumentation.

\subsection{Supply chain management and electronic mar- ketplaces-compatible or incompatible?}

\subsubsection{From a theoretical standpoint}

Theoretically, the relationship between EMs and supply chain management appears problematic. Co-operative supply chains aim to reduce the number of suppliers and form long-term strategic alliances that 'lock in' suppliers and 'lock out' competition, while EMs promote competition and allow buyers to search for suitable suppliers and support "transaction-based" partnering.

Economies have two basic mechanisms for co-ordinating the flow of materials or services through adjacent steps in the value chain-markets and hierarchies (Malone et al., 1987, 1989; Picot and Kirchner, 1987). Williamson categorises transactions into those that support co-ordination between multiple buyers and sellers, i.e., market transactions, and those that support co-ordination within the firm, as well as the industry value chain, i.e., hierarchy transactions (Williamson, 1975, 1981). Williamson points out that the choice of transaction will depend on a number of factors, including asset specificity, the parties' interest in the transaction, and ambiguity and uncertainty in precisely describing the transaction.

The electronic markets hypothesis developed by Malone et al. (1987) predicts that, all other things being equal, the introduction of information technology will lead to greater use of markets rather than hierarchies for economic transactions. Lower levels of two factors, asset specificity and complexity of description, will favour markets rather than hierarchies in a given industry.

A highly specific asset is more likely to be acquired through hierarchical co-ordination than through market co-ordination. Transactions involving asset-specific products often involve a long process of developments and adjustments for the supplier to meet the needs of the procurer, a process that favours the continuity found in a hierarchy (Malone et al., 1987).

A product with high description complexity is more likely to be acquired through hierarchical co-ordination because of higher transaction costs associated with the exchange of complex descriptions. In a market these complex descriptions must be obtained from many possible suppliers to allow comparisons. Thus, buyers of products with complex descriptions are more likely to work with a single supplier in a close, hierarchical relationship. However, some empirical studies focusing on interorganisational systems within the supply chain have shown that they have actually led to hierarchical co-ordination (Holland, 1995).

Another premise is the move-to-the-middle hypothesis developed by Clemons et al., 1993. Both theories are extensively discussed within the field of EMs (see e.g. Bakos and Brynjolfsson, 1993; Hess and Kemerer, 1994; Van Heck and Ribbers, 1997; Bailey and Bakos, 1997; Gregor et al., 1997).

The question if supply chain management and EMs are compatible, is in fact the question whether EMs are moving to hybrid forms within the market-hierarchy continuum (Williamson, 1975, $1981)$ as it was predicted by the move-to-the-middle hypothesis (Clemons et al., 1993).

\subsubsection{From a logistical standpoint}

From a logistical standpoint, supply chain management and EMs are not just compatible-EMs are to a high degree depending on supply chain management.

Crowley (1998) says that today every business competes in two markets: the marketplace, in which resources and products exist physically and 
the marketspace, which is a virtual world of electronic commerce in which the main object of transaction is information. Managing these two interacting value-adding processes, in the two mutually dependent realms, is seen as posing new conceptual and tactical challenges for every firm.

Graham and Hardaker (2000) argue that the marketplace is part of the web-based relationships in the supply chain, which could be divided into three company perspectives, namely business-tobusiness, business-to-consumer and marketspace. In this case, the marketspace involves the company, its partners, and its customers and provides the opportunities for developing communication interactions, including customer surveys and information exchange on such things as product warranty and service capabilities. Beyond that, it is proposed that, with marketspace reconfiguring the traditional value proposition, supply chain management needs to manage the organisational complexity of adopting a dynamic mix and emphasis between content, context and infrastructure. Integration along the supply chain in the virtual market can be viewed as being a mix of both formal and loose integration mechanisms, similar to the Internet infrastructure.

But the question is if Internet transactions and physical logistics are conflicting or complementary. Gurãl et al. (2001) argue that Internet commerce does not eliminate the need of physical logistics systems; in fact, it even increases their importance. The flow of information between the supply chain partners can be efficiently managed over the Internet, reducing the costs and increasing the speed and the quality of data transfer. On the other hand, the EM should organise a complementary physical logistics system in order to distribute material products to its clients. But so far this is done inadequately. Van Hoek (2001) claims that the supply chain dimension of e-business is largely neglected and poorly managed, while the mal-performance of logistics is currently hampering turnover and revenues of e-commerce applications in a severe way. If basic operational performance is not even assured, more advanced approaches of e-business will not take off, since the support for concepts in the physical domain is inadequate.
Furthermore, Gurãl et al. (2001) emphasise that EMs can subcontract the functions of the physical logistics system from other specialised firms. It can be said that the implementation of the Internet is changing the structure of the classical distribution channel, encouraging an increased specialisation of the physical delivery functions. The authors argue for value networking, in which the EM is organising and managing a complex portfolio of partnerships with physical logistics service providers. On the other hand, in many cases, the EM will decide to create its own physical assets in order to provide a consistent quality of product delivery. Benjamin and Wigand (1995), on the other hand, form a model that contains stakeholders in the value chain, which are connected to the national information superhighway. This "highway" encloses transportation of both physical goods and information and connects producers of information, producers of physical goods, electronic retailers (e-retailers), EMs, physical distribution networks, electronic channels and the market choice box. Beyond that, they argue that all stakeholders in the industry value chain must consider whether their place in the chain is threatened and, if so, what long-term strategies to experiment with. Those in the consumer value chain need to understand under what conditions the consumer will prefer to purchase from singlesource suppliers and EMs.

More practically oriented research are studies by Emiliani (2000) or by Gudmundsson and Walczuck (1999) because they bring insights of the supply chain management within, to specific kinds of EMs. While Emiliani (2000) describes the process for conducting B2B auctions over the Internet and presents common issues, process improvement opportunities, and the interpretation of auction results, Gudmundsson and Walczuck (1999) conceptualise the EM for logistics. Emiliani (2000) argues that an on-line auction is an attractive technological solution for reducing costs, but it does not help uncover the root causes of poor cost management within the buying firm. Further, the intermediaries understand commodity management, markets, and information technology very well, but do not understand supply chain management and lean production, as evidenced by 
contract terms and conditions. As a result, the author proposes that online auctions will delay the adoption of modern supply chain management methods and the implementation of lean production that are needed by both buyers and suppliers in order to truly eliminate waste and reduce total costs.

\section{Relevancy of supply chain management in differ- ent electronic market categories}

\subsection{Internet-enabled business relationships within electronic markets}

In the following section we analyse the relevancy of supply chain management for EM. The idea is to examine different types of relationship within different EM categories. While there are myriad aspects within a relationship among trading partners in an EM, three broad categories have been identified: transactional, information-sharing, and collaborative relationships (AMR, 1998). The suggestion is that barely transactional-oriented EMs are to a lower degree depending on supply chain management than collaborative-oriented EMs.

Transactions within a buyer-seller relationship involve the activities carried out to execute the buyer's purchase of a commodity. These activities involve information notifying the buyer and seller that a purchase is taking place and that funds need to be exchanged. Historically, EMs have mostly dealt with the transactional aspects of a relationship. Thus automation has focused on sending purchase orders and invoices and on transferring funds. The only information that must be transmitted in this type of relationship that is that needed to execute a purchase.

The next trading relationship involves information sharing or data exchange. This involves at least one of the following arrangements (Noekkenved, 2000): (a) The partners are given access to a system that has the shared information in it, or (b) one partner transmits shared information to the other partner. For example, Web-based catalogues allow buyers to electronically view product information. Various types of information can be shared by buyer or seller, either before or after a purchase is made. This information may involve the seller's offerings or the buyer's future needs. Historically, little information has been electronically shared among trading partners. The recipient is using the data as-is and is not providing feedback (one-directional information flow); on the other hand information-sharing does little to reduce the uncertainty faced by trading partners in determining future demand, and does not grant the opportunity for the other partner to provide his or her own insight and knowledge of customer needs or other market opportunities. In addition, there is little opportunity to work together on matching supply with anticipated customer demand.

To further enhance a buyer-seller relationship some progressive companies are moving towards collaborative relationships, in which they are "working jointly with others, especially in an intellectual endeavour" (Noekkenved, 2000). Collaborative efforts enable trading partners to work together to better understand future demand and to put plans in place to satisfy it profitably. In a collaborative relationship, information is not just exchanged and transmitted, but it is also jointly developed by the buyer together with the seller. For example, in the case of working collaboratively on customer requirements, trading partners might collaborate on new product designs and customer demand forecasts. Generally this information deals with future product plans and needs.

\subsection{Different electronic marketplaces require supply chain management}

In the section above we elaborated on three types of information-related relationships within an EM. That is, some information may be exchanged on a transactional basis, some on an information-sharing basis, and some on a collaborative basis. Beyond this, collaborative relationships require that the other two types have already been implemented. It seems to be evident that within the spread of these relationships, supply chain management seems to be more appropriate, since the type of relationship within the EM is more of a collaborative kind. 
In the following sections we categorise EMs in several ways and discuss the buyer-supplier relationship. EMs can be distinguished by the following classifications:

(i) the more stakeholder-focused way divides EMs into buyer-oriented, seller-oriented and neutral;

(ii) the most straightforward categorisation is in vertical and horizontal EMs;

(iii) the more economic and price-focused classification divides EMs into markets with fix or variable pricing mechanism (auction, exchange, catalogues);

(iv) EMs can be classifies regarding to the purchasing process "What" and "How" businesses purchase (manufacturing vs. operating inputs; spot vs. system sourcing);

(v) another possibility is to distinguish into open and closed EMs;

(vi) the more process focused categorisation is to distinguish into supported transactions phases (information exchange, negotiate, settlement, after-sales);

(vii) and finally by the market mechanism (aggregation and matching).

\subsubsection{Buyer-oriented, seller-oriented and neutral EMs}

The operator that runs the EM and can be, depending on the business model (Timmers, 1998), an autonomous operator (i.e. ChemConnect), a group of market participants (=Consortia EMs like Covisint by General Motors, Ford, DaimlerChrysler), a single supplier or buyer (i.e. Deutsche Telekom's MarketPlace, Auto-Xchange by Ford) or a service provider, such as WorldWideTesting (Schmid and Lindemann, 1998). The EM operator or consortia runs either a buyer-oriented, selleroriented or neutral EM.

The role of a buyer-oriented marketplace is to aggregate buyers. Buyer-oriented marketplaces such as CommerceOne's MarketSite concentrate primarily on creating efficiencies for the corporate buyer. Buyer-oriented networks generally have several objectives, that is to drive procurement costs down for the participating buyers, to allow buyers to "aggregate their expenditure", to reduce administration costs, to increase visibility and to facilitate global sourcing. Buyers have the ability to join forces with other large buyers to create procurement syndicates, which can demand more favourable pricing and trading terms. All three types of relationships are aligned to increase benefits to buyers.

The seller-oriented aggregated marketplace concentrates on bringing multiple sellers together into a central catalogue and product information repository (i.e. Build-Online, e-Steel). Where buy side marketplaces target the procurement needs of corporations, seller-oriented marketplaces focus on sales. The key to a seller-oriented marketplace is to provide multiple sellers a forum to present their catalogues and conduct in trade with as many buyers as possible - in other words to aggregate the "content" that will meet the buyers needs. Seller-oriented marketplaces also have the ability to aggregate their sellers, acting as a service provider, wrapping products and services together and offering them to buyers, to EMs, and to buyeroriented aggregated networks directly. All types of relationships are aligned to increase benefits to sellers.

Neutral e-markets, driven by a third part (i.e. CPGmarket, Tribon Marketplace, ChemConnect) are the true market makers because they are equally attractive to sellers and buyers. However, these marketplaces often face the "chicken-andegg" problem: buyers do not want to participate unless there are a sufficient number of sellers, and sellers do not want to participate unless there are a sufficient number of buyers. In addition, these neutral markets also have to overcome channel conflicts to persuade more powerful players to participate. Making deals with more powerful players to gain liquidity is a threat to their independence and neutrality.

\subsubsection{Vertical or horizontal EMs}

Fundamentally, there are two kinds of EMs vertical and horizontal EMs. Vertical EMs are industry-specific, i.e. ChemConnect, Chemdex, OneChem, and e-Chemicals in the chemical industry. Vertical marketplaces aggregate supply or demand in vertical industries. Vertical marketplaces require a good deal of industry knowledge. 
They optimise buyer-seller relationships in a specific industry, such as chemicals, metals, energy, and telecommunications.

Horizontal EM makers facilitate the purchase and sale of goods and services used by a range of industries (i.e. Asista, Deutsche Telekom MarketPlace, BizBuyer, Grainger). Horizontal marketplaces are also known as "functional marketplaces" because they cut across industries to optimise specific functions in an enterprise, including human resources, procurement, logistics and marketing. A consideration of whether vertical or horizontal markets are more transactional or collaborative does not appear to be suitable.

In addition, there are companies that provide vertical and horizontal EMs with the technical platform. They have become known as Application Service Providers (ASP). Examples are TRADEX Technologies, The Sun/Netscape Alliance or Trading Dynamics. These companies are known as "enablers" and offer tools such as information-publishing tools, catalogue software, transactional capabilities, payment services, or customer relationship management functionality (Fig. 2 gives an overview).

\subsubsection{Pricing mechanism}

The pricing mechanism used can also categorise the EM (Kaplan and Sawhney, 1999; Schmid, 1999). In some e-markets like electronic catalogues

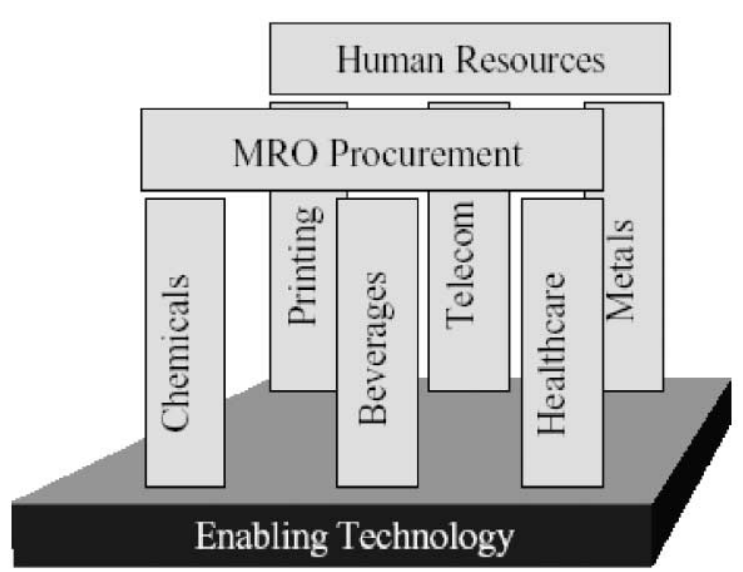

Fig. 2. Horizontal (functional) and vertical (industry-specific) EMs. prices are fixed, portals do not have a pricing mechanism, while in auction or exchange models a dynamic price-building mechanism is approached.

Online catalogues (i.e. Papersite, Requisite Technology or Harbinger) take the paper-based catalogues of multiple vendors, digitise the product information and provide buyers with one-stop shopping over the Internet. Online catalogues are optimally suited for markets where the supply and demand sides of a market are highly fragmented. Online catalogues are less transactional. They open a wider range of information sharing and collaboration.

An EM with auctions price mechanism (i.e. USBid, Manheim Online, GoCargo) provides a venue for the purchase and sale of unique items such as surplus inventory, used capital equipment, discontinued goods, perishable items, or refurbished products. In a traditional auction, the competitive bidding process results in upward price movement (Klein, 1997; Vigoroso, 1999; Emiliani, 2000; Baatz, 1999). The reverse auction (i.e. econia.com, ChemConnect, CPGmarket), a format in which sellers compete for a buyer's offer to purchase, results in downward price movement. Marketplaces with an exchange model work as stock exchanges. A real-time bid-ask matching process is necessary as well as marketwide price determination. Any kind of dynamic price-building is focused on price reduction and transactional-oriented.

Portals bring together buyers and sellers in commerce-oriented settings, but do not enable negotiation transactions (i.e. PharmSource Information Services). Buyers and sellers close deals offline.

\subsection{4. "What \& how" businesses purchase}

Using the buying behaviour as classification criteria, Kaplan and Sawhney (2000) classify EMs into four categories, namely $M R O$ hubs, yield managers, exchanges and catalogues (Fig. 2).

"What businesses buy" can roughly be divided into manufacturing inputs and operating inputs; manufacturing inputs are raw materials and components that go directly into a product or a process, and operating inputs, which are not part of the finished products, operating inputs, often 
called maintenance, repair and operating goods (MRO), include office supplies, spare parts, airline tickets and services. Manufacturing inputs tend to be industry-specific, whereas operating inputs are not. In most cases manufacturing inputs require a higher degree of information sharing and collaboration (Kaplan and Sawhney, 2000).

The second distinction in business purchasing is "how products and services are bought". Companies can either engage in systematic sourcing or in spot sourcing. Systematic sourcing involves negotiated contracts with qualified suppliers. Because they tend to be long term, the buyers and sellers often develop close relationships. In spot sourcing, the buyer's goal is to buy a product at the lowest possible cost and to speculate. Commodity trading for things like oil, steel, and energy exemplifies this approach. Spot transactions rarely involve a long-term relationship with the buyer, in fact, buyers on the spot market often do not know who they are buying from. In most cases systematic sourcing involves more need for information sharing and collaboration (Kaplan and Sawhney, 2000).

\subsubsection{Open or closed EMs}

In addition, it is suitable to distinguish between open and closed e-markets (Steyer, 1998; Schmid, 1999). An open e-market characterises the public accessibility for those who follow the e-market's rules. By contrast a closed e-market is only open for certain suppliers and customers. Table 2 contains some other differences.

Van Heck and Ribbers (1997) use a so-called reach/scope framework for IT infrastructures in the EM context. They propose that an effective EM with long reach (e.g., a relatively open structure allowing many participants) will have a low scope (simple functionality). Agreeing on a highly complex functionality with many participants is simply too difficult to accomplish. EMs with short reach (relatively closed structure, resulting in few participants) may have high scope (complex functionality).

\subsubsection{EM transaction phases}

EMs facilitate exchange of goods, information, services, and payments associated with market transaction (Bakos, 1998; Schmid, 1999). Four phases of such transactions can be distinguished: information, negotiation, settlement and after-sales (see Figs. 3 and 4).

In the information phase, buyers identify and evaluate their needs and possible sources to fulfil them. At the same time, sellers arrange for providing their goods and identifying potential customers. To a large extent, these steps evolve around exchange of information. The information phase ends for a market participant with the submission of an offer. With the receipt of an offer, the second phase starts, that is the negotiation phase. Potential buyers and sellers negotiate the terms of the intended transaction by jointly identifying possible solutions with the goal of reaching a consensus. The result is a legal-binding contract, representing the agreement between the market partners. In the settlement phase, the agreed-upon terms of the contract are fulfilled. Depending on the type of the exchanged goods or service as well as the participating partners, the settlement phase

Table 2

Closed and open EMs

\begin{tabular}{|c|c|}
\hline Closed e-market & Open e-market \\
\hline $\begin{array}{l}\text { - Between companies (B2B) } \\
\text { - Closed, often industry-specific "clubs" } \\
\text { - Limited number of involved companies } \\
\text { - Closed company-owned network (firewalls) } \\
\text { - Known and connected partners } \\
\text { - Security through networking } \\
\text { - The market is a club } \\
\text { - High degree of information sharing and collaboration }\end{array}$ & $\begin{array}{l}\text { - Between companies (B2B), companies and consumers (B2C, C2B) or } \\
\text { between companies and authorities } \\
\text { - Open (global) market } \\
\text { - Unlimited number of participants } \\
\text { - Open, unprotected network } \\
\text { - Known and unknown partners } \\
\text { - Security and authenticity necessary } \\
\text { - The net is the market } \\
\text { - Low degree of information sharing and collaboration }\end{array}$ \\
\hline
\end{tabular}




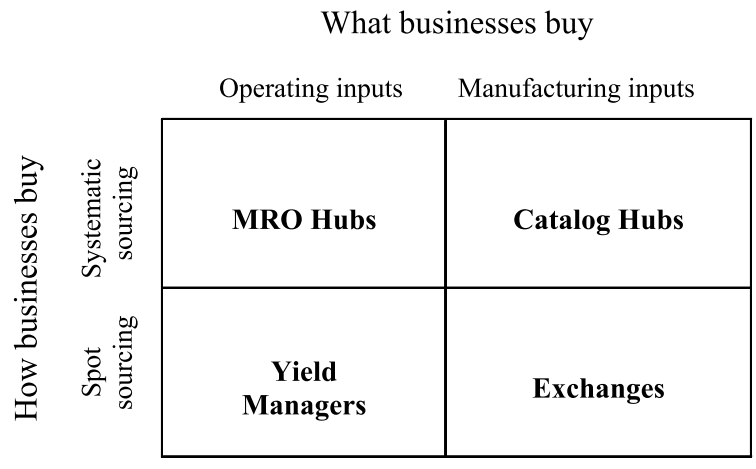

Fig. 3. EM classification by Kaplan and Sawhney (2000).

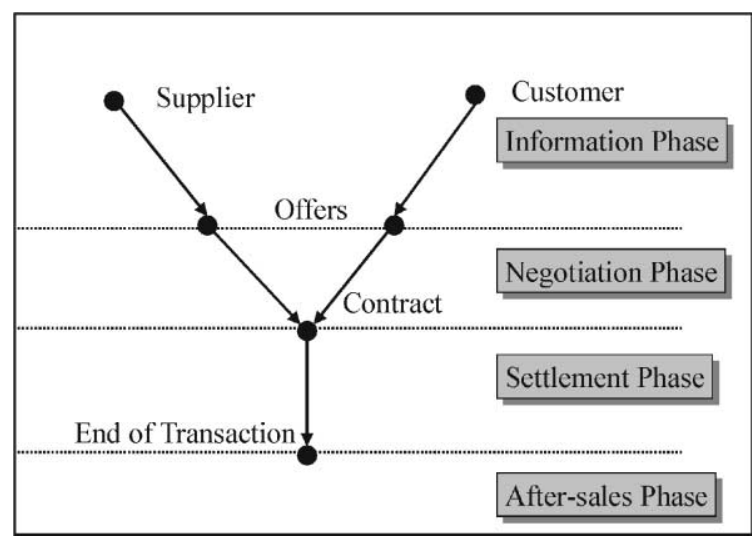

Fig. 4. Phases of market transactions (compare with Gebauer (1996), Schmid and Lindemann (1998) and Scharl (2000)).

can be an initiator of secondary market transactions (e.g. logistics and financial services). Result of this phase is the fulfilment of the contract. Scharl (2000) adds a fourth phase, namely after-sales, including after-sales product support, customer service, and the evaluation of the transaction's outcome.

Scharl argues that the first and last are explicit market transaction phases, whereas Schmid and Lindemann say that an EM supports all phases or at least the information phase of a market transaction. The Internet surrounds EMs with all kinds of transaction facilities. Portals, for example, support only the information phase. They bring together buyers and sellers in commerce-oriented settings, but do not enable negotiation transac- tions. Some EMs facilitate all transactions, including after-sales service. A number of EMs offer secondary transactions and others, again, have outsourced them. The more the transaction phases that are supported and the more non-buying/nonselling transactions that are in addition possible, the more opportunities for information sharing and collaboration there will be. Some innovative EMs have broadened their service by providing additional services such as facilitating collaboration in product development or order management (i.e. Transora, Envera, Covisint).

\subsubsection{Market mechanisms}

As we think about the differences between systematic and spot purchasing, it becomes obvious that the market-making mechanism that is appropriate for MRO and catalogues are quite different from the mechanism used, for example, by exchanges. EMs can create value by two fundamentally different mechanisms: aggregation and matching (Segev and Beam, 1999; Bakos, 1991, 1998; Schmid, 1999).

EMs that use the aggregation mechanism bring together a large number of buyers and sellers under one virtual roof. They reduce transaction costs by providing one-stop shopping. The aggregation mechanism is static in nature because prices are pre-negotiated. An important characteristic of this mechanism is that adding another buyer to the market benefits only the sellers, and adding another seller benefits only the buyers. Unlike the static aggregation mechanism, the matching mechanism brings buyers and sellers together to negotiate prices on a dynamic and real-time basis. Therefore the matching mechanism leads to more transactional relationships. The matching mechanism can work in the form of auctions. In the matching mechanism, the roles of the players are fluid: buyers can be sellers, and vice versa. Therefore, adding any new member to the EM increases the market's liquidity and thus benefits both buyers and sellers, while user of catalogues benefit only from the aggregation mechanism, user of exchanges benefit from both aggregation and matching. Therefore, successful exchanges will reap greater benefits from being first movers. That makes matching a more powerful business model 
than aggregation. At the same time, however, the matching mechanism is far more complex.

\section{Further research issues}

There is a rapidly growing interest in EMs, which is currently covered in more than 100 papers and articles. Unfortunately, most of the published work, in research and practice, is biased towards e-commerce, sales and marketing or is simply counting all sorts of possible values and cost savings. The supply chain dimension of EMs is for the most part mistreated and handled insufficiently. The paper has covered relatively new ground in logistics that has been preliminarily studied in various other disciplines and that is being created by developments in information technology and revolutionary changes in business models, brought about by the Internet.

The paper describes how supply chain management for EMs can be examined that is by analysing different types of EM relationships (transactional, information-sharing, collaborative) within different EM categories. Beyond the per- spective of supply chain management, a deeper examination of the relationships within certain marketplace category is necessary. Based on the results of this literature review, the author suggests the following research questions, which should be empirically tested in future research:

1. Beyond the perspective of supply chain management, the choice of an EM is depending on the different EM categories:

(i) buyer-oriented, seller-oriented or neutral;

(ii) vertical or horizontal;

(iii) fix or variable pricing mechanism;

(iv) manufacturing or operating inputs; spot or system sourcing;

(v) open or closed;

(vi) supported transactions phases;

(vii) aggregation or matching mechanism.

2. The type of the EM relationship transactionaloriented, information-sharing, or collaborativeoriented has an influence on the successful use of EMs within a supply chain agreement.

\section{Appendix A. Methodological approach}

\begin{tabular}{ll}
\hline Research strategy & Description \\
\hline Used key words & • "Electronic market"; "Electronic marketplace"; "Electronic \\
& exchange"; "Electronic auction"; "Electronic SCM"; "Internet \\
& exchange"; "Electronic hub" \\
Time period & - November 2000 until April 2001 \\
Search engines & - www.google.com, www.yahoo.com, www.business.com \\
Scientific on-line literature & - ABI Inform (ProQuest) \\
data bases & - Emerald Library \\
& - ACM Digital Library \\
Specific hard copy journal & - All volumes of the Journal of Electronic Markets \\
research Proceedings & - ACM-Proceedings \\
Additional research servers & - Goldman Sachs (http://www.gs.com/hightech/research/) \\
& - Deloitte Research (http://www.dc.com/obx/pages.php?Name=eviews), \\
& - PricewaterhouseCoopers (http://www.pwc.de/30000_publikationen/ \\
& $\left.30000 \_p u b l i k a t i o n e n . h t m\right)$
\end{tabular}




\begin{tabular}{|c|c|}
\hline Research strategy & Description \\
\hline & $\begin{array}{l}\text { - Nerve Wire (http://www.nervewire.com) } \\
\text { - Deutsche Bank (http://www.dbresearch.de/) } \\
\text { - Gartner Group (http://gartner12.gartnerweb.com/public/) } \\
\text { - Bloor Research (http://www.bloor-research.com/) } \\
\text { - Aberdeen Group (http://www.aberdeen.com/) } \\
\text { - AMR Research (http://www.amrresearch.com/practices/scs.asp) } \\
\text { - Forrester (http://www.forrester.com/) } \\
\text { - Xephon (http://www.xephon.com/) } \\
\text { - Metagroup-Commerce Chain Management (http://www.metagroup.com/ } \\
\text { - } \text { McKmunities/ccm/ccm.shtml) } \\
\text { - Accenture Consulting (http://www.accenture.com/) } \\
\text { - IDC (http://www.idc.com/) } \\
\text { - Montgomery Research (http://www.montgomeryresearch.com/) }\end{array}$ \\
\hline Internetportals & $\begin{array}{l}\text { - FTC on Consumer Protection: E-Commerce \& the Internet: (http://www.ftc. } \\
\text { gov/bcp/menu-internet.htm) } \\
\text { - E-Commerce Times: http://www.ecommercetimes.com/ } \\
\text { - "Dissertationen Online": (http://www.educat.hu-berlin.de/diss_online/ } \\
\text { biblio.html) } \\
\text { - The Hub for B2B e-Commerce White Papers: (http://www.nmm.com/ } \\
\text { reports/index.asp) } \\
\text { - B2b exchange Database: (http://www.b2bexchanges.com/list.cfm) } \\
\text { - abour.com: (http://onlineretailing.about.com/onlineretailing/cs/ } \\
\text { b2bexchanges/index.htm?once = true\&amp); } \\
\text { - European Electronic Commerce Website: (http://europa.eu.int/ISPO/ } \\
\text { ecommerce/Welcome.html) } \\
\text { - Encyclopedia of the New Economy: (http://hotwired.lycos.com/special/ene/) } \\
\text { - e-Marketer: (http://www.emarketer.com/) } \\
\text { - e-Business Central: (http://www.montgomeryresearch.com/ebcentral/) } \\
\text { - Print-The Premier New Economy Business Technology Portal: (http:// } \\
\text { www.brint.com/interest.html) } \\
\text { - Electronic Markets: (http://www.electronicmarkets.org/) } \\
\text { - Skillbot-Community Finder: (http://www.skillbot.com/community/ } \\
\text { community.htm) } \\
\text { - DMOZ e-Commerce: (http://dmoz.org/Business/E-Commerce/) } \\
\text { - DMOZ e-markets: (http://dmoz.org/Business/E-Commerce/Marketplaces/) } \\
\text { - WSJ.com-Special Report: E-Commerce: (http://interactive.wsj.com/ } \\
\text { public/current/summaries/ecom00-2.htm) }\end{array}$ \\
\hline
\end{tabular}

\section{References}

AMR, 1998. Are We Moving From Buyer and Seller to Collaborators? SCM Report, American Manufacturing Research Inc.
Ariba, 2000. B2B Marketplaces in the New Economy. Research Report (Downloadable from website http://www.ariba. com/com_plat/white_paper_form.cfm).

Baatz, E., 1999. Online auctions start to pick up stream. Purchasing Magazine 21, 546-556. 
Bailey, J.P., Bakos, J.Y., 1997. An exploratory study of the emerging role of electronic intermediaries. International Journal of Electronic Commerce 1 (3), 7-20.

Bakos, J.Y., 1991. A strategic analysis of EM. MIS Quarterly 15 (4), 295-310.

Bakos, J.Y., 1998. The emerging role of EM on the Internet. Communications of the ACM 41 (8), 35-42.

Bakos, J.Y., Brynjolfsson, E., 1993. From vendors to partners: Information technology and incomplete contracts in buyersupplier relationships. Journal of Organisational Computing 3 (3), 301-328.

Benjamin, R., Wigand, R., 1995. Electronic markets and virtual value chains on the information superhighway. Sloan Management Review, Winter, 62-72.

Bradley III, D.B., Peters, D., 1997. Electronic Marketplaces: Collaborate If You Want To Compete. 42nd World Conference International Council for Small Business, San Francisco, June.

Clemons, E.K., Reddi, S.P., Row, M.C., 1993. The impact of information technology on the organisation of economic activity: The "move to the middle" hypothesis. Journal of Management Information Systems, Armonk, Fall.

Coppel, J., 2000. E-Commerce: Impacts and Policy Challenges. OECD Economics Department, Working Paper No. 252, Organisation for Economic Co-operation and Development OECD, June, (Downloadable from website http://www.oecd.org/eco/eco).

Crowley, J.A., 1998. Virtual logistics: Transport in the marketspace. International Journal of Physical Distribution and Logistics Management 28 (7), 547-574.

Dai, Q., Kauffman, R.J., 2000. Business Models For Internet Based E-Procurement Systems and B2B EM: An Exploratory Assessment. 34th Hawaii International Conference on Systems Science, Maui, Hawaii, January.

(The) Economist, 2000. Shopping Around the Web: A Survey of e-Commerce, 26 February. (Downloadable from website http://www.economist.com/editorial/freeforall/20000226/ index_survey.html).

Emiliani, M.L., 2000. Business-to-business online auctions: Key issues for purchasing process improvement. Supply Chain Management: An International Journal 5 (4), 176-186.

Gebauer, J., 1996. Informationstechnische Unterstützung von Transaktionen. Gabler, Wiesbaden.

Graham, G., Hardaker, G., 2000. Supply Chain Management across the Internet. International Journal of Physical Distribution and Logistics Management 30 (3/4), 286295.

Gregor, S., Newman, S., Larner, T., 1997. The Australian Meat Industry, the EM Hypothesis and Internet Marketing. 10th International Bled Electronic Commerce Conference, Bled, Slovenia, 9-11 June.

Gurãl, C., Ranchhod, A., Hackney, R., 2001. Internet transactions and physical logistics: Conflict or complementarity. Logistics Information Management 14 (1/2), 33-43.

Gudmundsson, S.V., Walczuck, R., 1999. The development of electronic markets in logistics. International Journal of Logistics Management 10 (2), 99-113.
Henderson, D.R., 1984. Electronic marketing in principle and practice. American Journal of Agriculture Economics 66 (5), 848-853.

Hess, C.M., Kemerer, C.F., 1994. Computerised loan origination systems: An industry case study of the electronic market hypothesis. MIS Quarterly 18 (3), 251-275.

Himberger, A., Krähenmann, N., Langenohl, T., Ritz, D., Schmid, M., Zbornik, S., 1991. Elektronische MärkteGrundlagen und Forschung. Arbeitsbericht/Bericht IM HSG/CCEM 14, September, St. Gallen: Institut für Wirtschaftsinformatik.

Holland, C.P., 1995. Co-operative supply chain management: The impact of interorganizational information systems. Journal of Strategic Information Systems 4 (2), 117-133.

Kaplan, S., Sawhney, M., 2000. E-hubs: The New B2B Marketplaces. Harvard Business Review (May/June), 97-104.

Klein, S., 1997. Introduction to electronic auctions. International Journal of Electronic Markets 7 (4), 3-6.

Lipis, L.J., Villars, R., Byron, D., Turner, V., 2000. Putting Markets into Place: An e-Marketplace Definition and Forecast. (Downloadable from website http://www.idc.com).

Malone, T.W., Yates, J., Benjamin, R.I., 1987. Electronic markets and electronic hierarchies. Communications of the ACM 30, 484-497.

Malone, T., Yates, J., Benjamin, R., 1989. The Logic of Electronic Markets. Harvard Business Review, 166-172.

McCoy, J.H., Sarhan, M.E., 1988. Livestock and Meat Marketing. AVI Book.

Mueller, R.A.E., 2000. Emergent E-Commerce in Agriculture. Agriculture Issues Center, AIC Issues Brief (14), December.

Nash, K.S., 2000. Reality Check. Computerworld 5, 58-59.

Noekkenved, C., 2000. Collaborative Processes in e-Supply Networks-Towards Collaborative Community B2b Marketplaces. Research Report. PricewaterhouseCoopers.

Obrecht, J., 2000. Playing e-hub Name Game. Netb2b.com, 3 July, BtoB, p. 9.

Picot, A., Kirchner, C., 1987. Transaction cost analysis of structural changes in the distribution system: Reflections on institutional developments in the federal Republic of Germany. Journal of Institutional and Theoretical Economics $143,62-81$.

Scharl, A., 2000. Evolutionary Web Development. Applied Computing. Springer, Berlin.

Schmid, B., 1993. Elektronische Märkte. Wirtschaftsinformatik 35 (5), 465-480.

Schmid, B., Grütter, R., Schmid-Isler, S., Stanoevska, K., Stähler, P., 1998. Ein Glossar für die NetAcademy (1) Institute for Media and Communications Management, University of St. Gallen, March (Downloadable from website http://www.netacademy.org).

Schmid, B.F., Lindemann, M.A., 1998. In: Elements of a Reference Model for EM. 31st Hawaii International Conference on System Sciences (HICCSS-31). IEEE Computer Society Press, Hawaii, USA, pp. 193-201.

Schmid, B.F., 1999. Elektronische Märkte-Merkmale, Organisation und Potentiale. The $\mathrm{mcm}$ institute. University of 
St. Gallen, Switzerland. (Downloadable from website http:// www.netacademy.org).

Segev, A., Gebauer, J., Faeber, F., 1999. Internet-based Electronic Markets. EM-International Journal of Electronic Markets 9 (3).

Segev, A., Beam, C., 1999. Brokering strategies in electronic commerce markets. Proceedings of the first ACM Conference on Electronic Commerce, 167-176.

Steyer, R., 1998. Ökonomische Analyse elektronischer Märkte. Working paper WI 1, Chair for Business Administration, Johannes Gutenberg-University, Mainz. (Downloadable from website http://wi.bwl.uni-mainz.de/arbeitspapiere/arbarbeitspapiere.html).

Tapscott, D., Ticoll, D., Lowy, A., 2000. Digital Capital-Harnessing The Power of Business Webs. Harvard Business School Press, Boston, MA.

Timmers, P., 1998. Business Models for Electronic Markets. EM-International Journal of Electronic Markets 8 (2), 3-8.

Van Heck, E., Ribbers, P.M.A., 1997. Economic effects of EM: An analysis of four cases in the dutch flower and transport industries. In: Nunamaker, J.F., Sprague, R.H. (Eds.), Information Systems-Organisational Systems and Technology. Proceedings of the 29th Annual Hawaii International Conference on System Sciences. IEEE Computer Society Press, Los Alamitos, pp. 407-415.

Van Hoek, R., 2001. E-supply chains-virtually non-existing. Supply chain management: An International Journal 6 (1), 21-28.

Vigoroso, M., 1999. Are Internet Auctions ready to gear up? Purchasing Magazine 11, 85-86.

Weber, B.W., 1993. How financial markets are going on-line. EM-International Journal of Electronic Markets 3 (3), 6-8.

Williamson, O.E., 1975. Markets and Hierarchies: Analysis and Antitrust Implications. Free Press, New York.

Williamson, O.E., 1981. The economics of organisation: The transaction cost approach. American Journal of Sociology 87, 548-577.

Wise, R., Morrison, D., 2000. Beyond the exchange- the future of B2B. Harvard Business Review, 86-96. 